\title{
PPAR gamma pro12Ala polymorphism and type 2 diabetes: a study in a spanish cohort
}

José Pablo Miramontes González ${ }^{1,2,5,7^{*}}$, Clara Cieza Borrella², Rafael Mayoral ${ }^{3,6}$, Luis Corral Gudino ${ }^{4}$, Ciel Makena Hoghtower ${ }^{5}$ and Rogelio González Sarmiento ${ }^{2,7,8}$

*Correspondence: jpmiramontes@hotmail.com

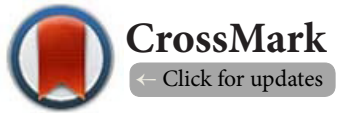

${ }^{1}$ Vascular Risk Unit, Department of Internal Medicine, University Hospital of Salamanca, Salamanca, Spain.

${ }^{2}$ Molecular Medicine Unit. Department of Medicine. University of Salamanca Spain.

${ }^{3}$ Department of Medicine, Division of Endocrinology and Metabolism, University of California-San Diego, La Jolla, California, USA.

${ }^{4}$ Internal Medicine, Hospital de Ponferrada.

${ }^{5}$ School of Medicine, University of California-San Diego, La Jolla, California, USA.

${ }^{6}$ Networked Biomedical Research Center and Digestive Diseases-CIBERehd, Barcelona, Spain.

${ }^{7}$ Institute for Medical Research of Salamanca (IBSAL), University of Salamanca-SACYL-CSIC, Spain.

${ }^{8}$ Institute of Molecular and Cellular Biology of Cancer, University of Salamanca-CSIC, Spain.

\begin{abstract}
Type 2 diabetes (T2D) is a disease whose occurrence is increasing prevalent in westernized civilizations and is responsible for the proliferation in the morbidity and total mortality of patients with cardiovascular diseases, worldwide. However, the complexity in the treatment and prevention of T2D arises from the intricacy of the many physical and biological factors involved in its etiology. Impaired pathways for insulin signaling have been implicated as one the many factors in the development of T2D Individual peroxisome proliferator-activated receptors (PPARs) have previously exhibited associations with alterations of lipid profiles, fat tissue and T2D and displayed complications derived from high levels of glucose. However, PPARgamma has not yet been associated with the development or developmental pathways of T2D. We performed an observational study a Spanish cohort in order to better understand the association between the SNP PPARgamma polymorphism Pro12Ala in our patients and the incidence of T2D and other cardiovascular complications. We study did not find a statistically significant relationship between the Pro12Ala and T2D development in our cohort, future observations will help us to know the association with vascular disease in patients with T2D.
\end{abstract}

Keywords: Diabetes type 2, PPAR $\gamma$, polymorphism pro12Ala, spanish cohort

\section{Introduction}

Diabetes is a chronic disease with high prevalence in the world. It results when the pancreas does not produce enough insulin or when the body cannot effectively use the insulin produced. The etiology of the disease comprises many metabolic alterations (obesity, lipid profile, hypertension) that are too involved with a variable influence on the progression of the disease. Having access to directly influence diabetes, genetically, will greatly facilitate the proper therapeutic production and eventually prevention of disease complications, progression, and development.

As a complex disease, diabetes continues to elude the medical and research communities. However, and unfortunately, the growing pandemic incessantly enhances the gap between treatments and treated. The number of people worldwide with diabetes is projected to rise from 171 million in 2000 to 366 million in 2030 [1]. In people over 65 years old the prevalence was $26.9 \%$ in 2007 . Diabetes is a critical risk factor for cardiovascular disease. Consequently, the importance of diabetic cases a greatly augmented, as they relate to elevated morbidity and mortality. Patients' vascular injury is accelerate due to their primary condition of diabetes, as previously reported, a total of 202,290 people were shown to need chronic dialysis or to be subjected to kidney transplantation a result of endstage kidney disease due to diabetes [2].

Type 2 Diabetes Mellitus (T2D), the most common type of diabetes (comprising $90 \%$ of patients worldwide), a complex metabolic disorder of multifactorial pathogenesis [3]. The genetic development of T2D is previously described [4]. The family of genes encoding the peroxisome proliferator-activated receptors (PPARs) are largely studied. The PPAR family of receptors are nuclear hormone receptors, which regulate lipid homeostasis and cellular differentiation and proliferation and modulate the immune response [5]. Activation of PPAR signaling pathways lead to an effect in lipid synthesis and oxidation, glucose uptake, inflammation, and expression of immunoregulatory genes [6]. As of yet three PPARs have been identified: PPAR-a, PPAR- $\delta$ and PPAR- $\gamma$.

The PPAR- $\gamma$ gene is located on chromosome 3 (Loc. 3p25, OMIM 601487), contains 9 exons and spans more than $100 \mathrm{~kb}$. PPAR- $\gamma$ exists in two major protein isoforms ( $\mathrm{g} 1$ and g2) and two minor forms (g3 and g4) created by alternate promoter 
González et al. Journal of Genetics Study 2014,

usage and alternative splicing at the $5^{\prime}$ end of the gene $[8,9]$. Yen et al., first identified a missense mutation resulting in the alanine substitution for proline at codon 12 (Pro12Ala) of the PPAR- $\gamma$ gene ( $r s 1801282)$ [10]. The structure and consequently the function of the protein may be affected by this amino acid change, since alanine favors the formation of the a-helix while proline prevents it. This polymorphism is located close to the $\mathrm{NH}_{2}$-terminus region of the protein, in the ligand-independent activation domain, and has been found to modulate the transcriptional activity of PPAR- $\gamma$. This activity is enhanced through phosphorylation by insulin $[11,12]$. PPAR- $\gamma$, is highly expressed in adipocytes, skeletal muscle, liver, and kidney, and has been shown to regulate expression of genes that mediate adipocyte differentiation, energy metabolism, and insulin action [7]. PPAR- $\gamma$ activation improves insulin sensitivity and glucose, adiponectin, and fatty acid uptake [8].

Alterations in insulin signaling pathways play a central role in the pathogenesis of T2D. The Pro12Ala polymorphism leads to a diminished stimulation of PPAR- $\gamma$ target genes, subsequent lowered levels of adipose tissue accumulation, which, in turn, may improve insulin sensitivity. We evaluated the allelic and genotypic distribution of the PPAR- $\gamma$ Pro12Ala polymorphisms in two cohorts of patients, with and without diabetes from the Vascular Risk Unit of the University Hospital of Salamanca (UHS).

\section{Materials and methods \\ Subjects}

This observational study included 298 Caucasians living in the region of Salamanca, in central Spain ( 155 females, $70.3 \pm 13.6$ years old; 143 males, $74.0 \pm 12.6$ years old). All subjects were selected from patients of the Vascular Risk Unit of the University Hospital of Salamanca. The individuals came from primary care centers to the control of hypertension, diabetes and/or other vascular risk factors. None of the patients had diagnosed vascular diseases. The patients were referred to the unit in order to participate in a program of the Vascular Risk Unit designed with the primary objectives to control vascular risk factors and follow the development of vascular disease over the subsequent five years, with an annual follow-up appointment. All subjects provided written informed consent, prior to entering the study. The protocol was approved by the ethics committee of the UHS following the Helsinki protocol.

\section{Determination of patients with diabetes}

Diabetes mellitus was established in patients using two diagnostic criteria, according to the American Diabetes Association (ADA) [13,14], fasting (no food or drink for 12 $\mathrm{hr}$ ) blood glucose level greater than $126 \mathrm{mg} / \mathrm{dl}$, as well as glycosylated hemoglobin $\left(\mathrm{HbA}_{11}\right)$ level greater than $6.5 \%$. The $\mathrm{HbA}_{1 \mathrm{c}}$ average in men was $6.82 \%$ and in women was $6.80 \%$. The classification of patients resulted in having 77 T2D subjects and 221 subjects without diabetes. This ration of subjects with and without T2D reflects the incidence of patients with alterations in glucose metabolism within the population residing in the surrounding region.

\section{DNA extraction and genotyping}

High molecular weight DNA was obtained from blood leukocytes, collected by venipuncture using a regular technique. DNA was isolated following standard procedures for Trizol reagent (Invitrogen, Carlsband, CA) extraction. The extracted DNA was stored at $-80^{\circ} \mathrm{C}$ until analyzed.

The analysis of the PPAR- $\gamma$ Pro12Ala polymorphism (rs1799983) was performed through real-time PCR allelic discrimination. Our specified primers were commercially premixed with the TaqMan MGB ${ }^{\circ}$ probe (C_1129864; Applied Biosystems, Foster City, California, USA). The TaqMan Universal PCR Master Mix No AmpErase UNG (Applied Biosystems, Foster City, Califronia, USA), containing DNA polymerase, was added to the prepared primer/probe mixture and analyses were carried out using an real-time PCR system (Applied Biosystems, Foster City, Califronia, USA).

\section{Statistical methods}

Logistic regression, including potential confounding factors age and sex as covariants, was applied to evaluate differences in allele and diploid genotype frequencies between subjects. A $p$-value $\leq 0.05$ was regarded as significant. Odds ratios and $95 \%$ confidence intervals $(\mathrm{OR} ; 95 \% \mathrm{Cl})$ were also calculated. The overall cohort size and statistical power was estimated according to the preliminary results obtained in this study, an estimate for $95 \%$ confidence intervals and $80 \%$ statistical power. All analyses were performed using the Statistical Package for Social Sciences (SPSS Inc, Chicago, Illinois, USA) version 19.20.

\section{Results}

The genotype distribution of the PPAR- $\gamma$ Pro12Ala polymorphism was $88.23 \%$ (C/C), $10.85 \%$ (C/G) and $0.90 \%$ $(\mathrm{G} / \mathrm{G})$, in patients without diabetes, versus $80.51 \%$ (C/C), $19.49 \%$ $(\mathrm{C} / \mathrm{G})$ and $0.00 \%(\mathrm{G} / \mathrm{G})$, in patients with T2D. Logistic regression analysis, used to compare genotypic frequencies between subject groups showed no significant differences, $p=0.115$.

\section{Discussion}

\section{Context and previous literature}

Several studies exploring the relationship between the PPAR-y Pro12Ala polymorphism and T2D, reportedly propose the Pro12Ala polymorphism as a strong candidate in the development of T2D [15], although the association between the metabolic disorder and the polymorphism is not consistently presented in the literature. Although previous studies in Caucasian populations published the Pro12Ala polymorphism does not correlate with the development of T2D [16,17], Gouda et al., conducted a meta-analysis involving 32,894 cases and 47,456 controls from 60 studies [18], concluding that the PPAR- $\gamma$ Pro12Ala polymorphism is positively associated with a reduction in the risk of T2D. Furthermore, the presence of other 
vascular risk factors has also been explored in relation to the association between PPAR- $\gamma$ and the onset of T2D. Similarly, other studies have demonstrated the PPAR- $\gamma / T 2 D$ onset in association with Body Mass Index lipid profiles, also extending studies to secondary organ damage resulting from diabetes, diabetic nephropathy and coronary heart disease [19-22].

\section{Advantages and limitations of this study}

The majority of presently published observational studies have explored the Pro12Ala polymorphism in patients with T2D and its association with vascular risk factors and the development of stroke, heart failure, kidney damage, and/or other related vascular disease. However, a principal advantage of our study design is that we are able to monitor our subjects over time, gauging physical, biochemical, and epigenetic trait changes, enabling continuous examination of the interaction between Pro12Ala genotypes and the development of vascular complications.

As with most studies involving human subject, our examination presented the following limitations: (A) The subjects were selected from an outpatient clinic, specializing in vascular risks, rather than chosen randomly from the surrounding community; (B) We excluded patients currently receiving treatments to control diabetes or alter glucose levels; (C) Some of the subjects, may have possibly altered their habits after enrolling in the primary care program; (D) Some of our subjects may have maintained relatively healthy lifestyles, including healthy diet and/or exercise, which could affect the estimation of $\mathrm{HbA}_{1 \mathrm{c}}$ levels.

\section{Conclusions and perspectives}

We were unable to observe a significant correlation between the PPAR- $\gamma$ Pro12Ala polymorphism and T2D in our Caucasian population, of Spanish descent. Consequently, we did not found a direct influence of the PPAR- $\gamma$ Pro12Ala polymorphism genetic variation in the development of diabetes disease. However, we enrolled the patients in a longitudinal study to explore the Pro12Ala polymorphism and to check if it takes an active part in the pathophysiology of T2D onset, through effects seen in adipose tissue, blood pressure, and vascular inflammation. Such effects increase the likelihood of developing vascular damage and long-term heart, brain, or kidney injury resulting from T2D in our cohort.

To ensure enhanced future treatment and preventative measures, the intricacies relating T2D and the PPAR- $\gamma$ Pro12Ala polymorphism must be further explored, in the context of diabetic vascular complications, in varied populations worldwide. A greater understanding of the evolution of this disease will greatly diminish its devastating effects.

\section{Competing interests}

The authors declare that they have no competing interests.

\section{Authors' contributions}

\begin{tabular}{|l|c|c|c|c|c|c|}
\hline Authors' contributions & JPMG & CCB & RM & LCG & CMH & RGS \\
\hline Research concept and design & $\checkmark$ & $\checkmark$ & -- & -- & -- & $\checkmark$ \\
\hline Collection and/or assembly of data & $\checkmark$ & -- & -- & - & -- & -- \\
\hline Data analysis and interpretation & $\checkmark$ & -- & $\checkmark$ & $\checkmark$ & -- & -- \\
\hline Writing the article & $\checkmark$ & -- & -- & -- & -- & -- \\
\hline Critical revision of the article & -- & -- & -- & -- & -- & $\checkmark$ \\
\hline Final approval of article & $\checkmark$ & $\checkmark$ & $\checkmark$ & $\checkmark$ & $\checkmark$ & $\checkmark$ \\
\hline Statistical analysis & -- & -- & -- & $\checkmark$ & -- & -- \\
\hline
\end{tabular}

\section{Acknowledgement}

Special thanks to Nieves Mateos for her help in the Molecular Medicine Unit. Department of Medicine. University of Salamanca (Spain). María Teresa Perrino and Lourdes Vicente Mosquete for their help with the sampling.

\section{Publication history}

Editor: James CS Chim, niversity of Hong Kong, China. Krzysztof Szyfter, Polish Academy of Sciences, Poland. Received: 05-Nov-2013 Revised: 29-Nov-2013

Re-Revised: 17-Jan-2014 Accepted: 25-Feb-2014

Published: 22-Mar-2014

\section{References}

1. Wild S, Roglic G, Green A, Sicree R and King H. Global prevalence of diabetes: estimates for the year $\mathbf{2 0 0 0}$ and projections for $\mathbf{2 0 3 0}$. Diabetes Care. 2004; 27:1047-53. | Article | PubMed

2. Data from the $\mathbf{2 0 1 1}$ National Diabetes Fact Sheet. 2011. | Website

3. Stumvoll M, Goldstein BJ and van Haeften TW. Type 2 diabetes: principles of pathogenesis and therapy. Lancet. 2005; 365:1333-46. I Article I PubMed

4. Zeggini E, Scott LJ, Saxena R, Voight BF, Marchini JL, Hu T, de Bakker PI, Abecasis GR, Almgren $P$ and Andersen $G$ et al. Meta-analysis of genomewide association data and large-scale replication identifies additional susceptibility loci for type 2 diabetes. Nat Genet. 2008; 40:638-45. | Article I PubMed Abstract I PubMed Full Text

5. Berger J and Moller DE. The mechanisms of action of PPARs. Annu Rev Med. 2002; 53:409-35. | Article | PubMed

6. Israelian-Konaraki Z and Reaven PD. Peroxisome proliferator-activated receptor-alpha and atherosclerosis: from basic mechanisms to clinical implications. Cardiology. 2005; 103:1-9. I Article I PubMed

7. Fajas L, Auboeuf D, Raspe E, Schoonjans K, Lefebvre AM, Saladin R, Najib J, Laville M, Fruchart JC, Deeb S, Vidal-Puig A, Flier J, Briggs MR, Staels $\mathrm{B}, \mathrm{Vidal} \mathrm{H}$ and Auwerx J. The organization, promoter analysis, and expression of the human PPARgamma gene. J Biol Chem. 1997; 272:18779-89. I Article I PubMed

8. Savkur RS and Miller AR. Investigational PPAR-gamma agonists for the treatment of Type 2 diabetes. Expert Opin Investig Drugs. 2006; 15:76378. | Article | PubMed

9. Fajas L, Fruchart JC and Auwerx J. PPARgamma3 mRNA: a distinct PPARgamma mRNA subtype transcribed from an independent promoter. FEBS Lett. 1998; 438:55-60. I Article I PubMed

10. Yen CJ, Beamer BA, Negri C, Silver K, Brown KA, Yarnall DP, Burns DK, Roth $\mathrm{J}$ and Shuldiner AR. Molecular scanning of the human peroxisome proliferator activated receptor gamma (hPPAR gamma) gene in diabetic Caucasians: identification of a Pro12Ala PPAR gamma 2 missense mutation. Biochem Biophys Res Commun. 1997; 241:270-4. | Article | PubMed

11. Deeb SS, Fajas L, Nemoto M, Pihlajamaki J, Mykkanen L, Kuusisto J, Laakso M, Fujimoto W and Auwerx J. A Pro12Ala substitution in PPARgamma2 associated with decreased receptor activity, lower body mass index and improved insulin sensitivity. Nat Genet. 1998; 20:284-7. 
González et al. Journal of Genetics Study 2014,

http://www.hoajonline.com/journals/pdf/2054-1112-2-1.pdf

| Article | PubMed

12. Werman A, Hollenberg A, Solanes G, Bjorbaek C, Vidal-Puig AJ and Flier JS. Ligand-independent activation domain in the $\mathrm{N}$ terminus of peroxisome proliferator-activated receptor gamma (PPARgamma). Differential activity of PPARgamma1 and $\mathbf{- 2}$ isoforms and influence of insulin. J Biol Chem. 1997; 272:20230-5. | Article | PubMed

13. Kilpatrick ES, Bloomgarden $\mathrm{ZT}$ and Zimmet PZ. International Expert Committee report on the role of the $\mathrm{A} 1 \mathrm{C}$ assay in the diagnosis of diabetes: response to the International Expert Committee. Diabetes Care. 2009; 32:e159. | Article | PubMed Abstract | PubMed Full Text

14. Gillett MJ. International Expert Committee report on the role of the A1c assay in the diagnosis of diabetes: Diabetes Care 2009; 32(7): 13271334. Clin Biochem Rev. 2009; 30:197-200. | PubMed Abstract | PubMed Full Text

15. Tonjes A and Stumvoll M. The role of the Pro12Ala polymorphism in peroxisome proliferator-activated receptor gamma in diabetes risk. Curr Opin Clin Nutr Metab Care. 2007; 10:410-4. I Article I PubMed

16. Qi $Q$ and Hu FB. Genetics of type 2 diabetes in European populations. J Diabetes. 2012; 4:203-12. | Article | PubMed Abstract | PubMed Full Text

17. Malecki MT, Frey J, Klupa T, Skupien J, Walus M, Mlynarski W and Sieradzki J. The Pro12Ala polymorphism of PPARgamma2 gene and susceptibility to type 2 diabetes mellitus in a Polish population. Diabetes Res Clin Pract. 2003; 62:105-11. | Article | PubMed

18. Gouda HN, Sagoo GS, Harding AH, Yates J, Sandhu MS and Higgins JP. The association between the peroxisome proliferator-activated receptorgamma2 (PPARG2) Pro12Ala gene variant and type $\mathbf{2}$ diabetes mellitus: a HuGE review and meta-analysis. Am J Epidemiol. 2010; 171:645-55. | Article | PubMed Abstract | PubMed Full Text

19. Passaro A, Dalla Nora E, Marcello C, Di Vece F, Morieri ML, Sanz JM, Bosi C, Fellin R and Zuliani G. PPARgamma Pro12Ala and ACE ID polymorphisms are associated with BMI and fat distribution, but not metabolic syndrome. Cardiovasc Diabetol. 2011; 10:112. | Article | PubMed Abstract | PubMed Full Text

20. Gonzalez Sanchez JL, Serrano Rios M, Fernandez Perez C, Laakso M and Martinez Larrad MT. Effect of the Pro12Ala polymorphism of the peroxisome proliferator-activated receptor gamma-2 gene on adiposity, insulin sensitivity and lipid profile in the Spanish population. Eur J Endocrinol. 2002; 147:495-501. | Article | PubMed

21. Zhang H, Zhu S, Chen J, Tang Y, Hu H, Mohan V, Venkatesan R, Wang $\mathrm{J}$ and Chen $\mathrm{H}$. Peroxisome proliferator-activated receptor gamma polymorphism Pro12Ala Is associated with nephropathy in type 2 diabetes: evidence from meta-analysis of 18 studies. Diabetes Care. 2012; 35:1388-93. | Article | PubMed Abstract | PubMed Full Text

22. Ho JS, Germer S, Tam CH, So WY, Martin M, Ma RC, Chan JC and Ng MC. Association of the PPARG Pro12Ala polymorphism with type 2 diabetes and incident coronary heart disease in a Hong Kong Chinese population. Diabetes Res Clin Pract. 2012; 97:483-91. | Article | PubMed

\section{Citation:}

Miramontes González JP, Cieza Borrella C, Mayoral R, Corral Gudino L, Makena Hoghtower C and González Sarmiento R. PPAR gamma pro12Ala polymorphism and type 2 diabetes: a study in a spanish cohort. J Genet Stud. 2014; 2:1. http://dx.doi.org/10.7243/2054-1112-2-1 